\title{
Relationship between Growth Hormone and Cytokines in Short Children Undergoing Growth Hormone Stimulation Testing
}

\author{
Kimberly Tafuri*, Denise Dixon, Katherine Markarian, Andrew Lane, Thomas A. Wilson \\ Department of Pediatrics, Stony Brook University, Stony Brook, NY, USA \\ Email: "Kimberly.Tafuri@stonybrookmedicine.edu
}

Received 14 October 2015; accepted 14 December 2015; published 17 December 2015

Copyright (C) 2015 by authors and Scientific Research Publishing Inc.

This work is licensed under the Creative Commons Attribution International License (CC BY). http://creativecommons.org/licenses/by/4.0/

(c) (i) Open Access

\section{Abstract}

Background: The relationship between growth hormone (GH) and cytokines remains unclear. Several studies have suggested that GH increases tumor necrosis factor (TNF)- $\alpha$ production in both children and adults. However, a number of studies have demonstrated a negative correlation between GH and TNF $\alpha$. The aim of this study is to explore the relationship between endogenous GH secretion and certain pro and anti-inflammatory cytokines in short children undergoing GH stimulation testing for evaluation for GH deficiency. Methods: Plasma growth hormone, TNF $\alpha$, CRP, IL-6, IL1- $\beta$, IL-4 and IL-10 levels are obtained at baseline and every 30 minutes for 150 minutes following two provocative agents (clonidine, and either arginine or glucagon). Results: Among the 23 children, 7 are found to be GH deficient. No significant differences in baseline TNF $\alpha$ levels are found between GH deficient and GH sufficient children. No correlation is identified between TNF $\alpha$ levels and GH levels during stimulation testing. Furthermore, no relationship is found between GH and pro-inflammatory cytokines or GH and anti-inflammatory cytokines. Conclusion: Our results do not demonstrate an acute relationship between endogenous GH secretion and the cytokines examined.

\section{Keywords}

Growth Hormone, Tumor Necrosis Factor- $\alpha$, Cytokines, CRP, IL-6, IL1- $\beta$, IL-4, IL-10, Growth Hormone Stimulation Testing, Clonidine, Arginine, Glucagon

\section{Introduction}

Increasing evidence in the literature supports an interaction between the immune system and the GH/Insulin like "Corresponding author.

How to cite this paper: Tafuri, K., Dixon, D., Markarian, K., Lane, A. and Wilson, T.A. (2015) Relationship between Growth Hormone and Cytokines in Short Children Undergoing Growth Hormone Stimulation Testing. International Journal of Clinical Medicine, 6, 912-918 http://dx.doi.org/10.4236/ijcm.2015.612119 
growth factor (IGF)-1 axis. TNF $\alpha$ is primarily secreted by activated macrophages and is capable of modulating GH secretion by interacting via the neuro-endocrine system [1] [2]. Conversely, GH has been shown to modulate the release of certain cytokines, particularly TNF $\alpha$ [3]. The GH receptor is a member of the type 1 cytokine receptor family and is expressed on human peripheral blood mononuclear cells. The presence of both GH and IGF-1 receptors on different lymphocyte subpopulations suggests a role for the GH/IGF-1 axis in immune function [4].

GH has been found to stimulate TNF $\alpha$ release in adults and children [5] [6]; however, there has been inconsistent documentation within the literature [7]-[9]. Research in hypophysectomized rats demonstrate a significant reduction in in vitro macrophage production of TNF $\alpha$ after stimulation with lipopolysaccharide [3]. Replacement with GH partially reverses this defect [3]. These findings suggest a role for GH in priming macrophages for TNF $\alpha$ synthesis [3]. Similarly, studies conducted in both normal statured and GH deficient children have illustrated significant increases in cytokine release, specifically TNF $\alpha$, after short term GH administration [5] [6].

To the contrary, other studies conducted in healthy young males as well as post-surgical patients demonstrate no effect of short term GH administration on cytokine secretion [7] [10]. Micahelous et al. also revealed no correlation between TNF $\alpha$ and GH levels in GH deficient or idiopathic short stature patients [8]. Similarly, Bozzola et al. appreciated no difference in baseline TNF $\alpha$ concentrations between controls and GH deficient children [11].

A number of studies have even demonstrated a negative correlation between TNF $\alpha$ and GH levels. Baseline TNF $\alpha$ concentrations in GH deficient children are significantly higher than those of controls and are decreased significantly to the levels of controls after GH supplementation [9]. Andiran \& Yordam found that children with isolated GH deficiency had elevated baseline TNF $\alpha$ compared to controls. Replacement with recombinant GH resulted in statistically significant lower TNF $\alpha$ levels at 6 months and 12 months when compared to baseline in the GH deficient children [9]. These findings suggested a potential inhibitory role for GH on TNF $\alpha$ release [9]. Chrysopoulo et al. found similar results in children suffering from burns. Children with acute burn injury had significantly elevated levels of TNF $\alpha$ at baseline. After 6 weeks of GH supplementation, TNF $\alpha$ concentrations decreased in the GH treated group when compared to placebo [12]. Studies in cystic fibrosis patients paralleled the findings in the acute burn injury population [13]. Given the conflicting results regarding the relationship between GH and TNF $\alpha$, this study was designed to explore the acute relationship between endogenous GH secretion and certain inflammatory markers, specifically pro-inflammatory cytokines, TNF $\alpha$, CRP, IL-6, IL1- $\beta$ and anti-inflammatory cytokines, IL-4 and IL-10, in short children undergoing GH stimulation testing for evaluation for GH deficiency.

\section{Patients and Methods}

\subsection{Patient and Study Design}

Twenty-three children with short stature who were undergoing a diagnostic GH stimulation test were studied. Children were excluded if they had an acute illness or fever on the day of testing, any underlying chronic disease, a history of whole body radiation or chemotherapy, recent or chronic NSAID use, a febrile illness or acute gastroenteritis two weeks prior to testing. Informed consent was obtained from the parents of all the children and assent was obtained from children > 11 yr. of age. The study was approved by the Stony Brook University IRB.

Baseline vital signs, including pain score was obtained prior to obtaining intravenous access. Samples were obtained for GH, TNF $\alpha$ (\#Y5000000DH), CRP, IL-6, IL1- $\beta$, IL-4 and IL-10 at baseline, and at 30, 60, 90, 120 and 150 minutes following stimulation with clonidine and either arginine or glucagon when arginine could not be obtained. The dose of clonidine was $0.05 \mathrm{mg} / \mathrm{kg}$ with a maximum of $0.250 \mathrm{mg}$, of arginine 0.5 grams $/ \mathrm{kg}$ intravenously over $30 \mathrm{~min}$ with a maximum of 30 grams, and of glucagon $0.03 \mathrm{mg} / \mathrm{kg}$ intravenously with a maximum of $1 \mathrm{mg}$. Samples for cytokine analysis were immediately centrifuged and stored at $-20^{\circ} \mathrm{C}$ until analyzed. In 6 out of 16 children subsequently found to be GH sufficient soluble TNF $\alpha$ receptor II was measured to determine if there was any difference between circulating levels of TNF $\alpha$ and the soluble TNF $\alpha$ receptor II.

\subsection{Measurement of Cytokine Levels}

The cytokine and CRP analyses were performed using the Bio-Plex 200 (Luminex) system. This is a bead-based 
multiplex analysis system that permits simultaneous analysis of up to 100 different biomolecules (proteins, peptides or nucleic acids) in a single micro plate well. Cytokine Assay Kits to measure IL-1 $\beta$, IL-4, IL-6, IL-10 and TNF $\alpha$ were purchased from Bio-Rad (Hercules, CA). The minimum detectable concentrations for these assays in $\mathrm{pg} / \mathrm{ml}$ were: $\mathrm{IL}-1 \beta=1.5$, IL- $4=0.1$, IL-6 $=1.56$, IL-10 $=1.54$ and TNF $\alpha=3.31$. All cytokines were diluted $1 / 4$ in assay buffer. The intra and inter assay coefficients of variation were $6 \%$ and $8 \%$ for IL- $1 \beta, 9 \%$ and $8 \%$ for IL-4, 7\% and $11 \%$ for IL-6, 5\% and $6 \%$ for IL-10 and $8 \%$ and $6 \%$ for TNF $\alpha$ The minimum detectable concentration for CRP was $2 \mathrm{pg} / \mathrm{ml}$. CRP was diluted 1/500 in assay buffer. The intra and inter assay coefficients of variation were $5.8 \%$ and $7 \%$ respectively.

\subsection{Measurement of GH Levels}

GH levels were performed by commercial laboratories or by the Stony Brook University Hospital laboratory depending upon the mandates of the insurance carrier.

\subsection{Measurement of Soluble TNF Receptor II}

Soluble TNF $\alpha$ receptor II (sTNFRII) was measured using Human sTNF RII/TNFRSF1B Quantikine ELISA Kit from R \& D systems (Minneapolis, MN). The assay range was from $7.8-500 \mathrm{pg} / \mathrm{ml}$. The intra and inter assay coefficients of variation were $2.3 \%$ and $3.5 \%$.

\section{Statistical Analysis}

Descriptive statistics were performed. Skewness and kurtosis were calculated using SPSS statistical software. Since the data do not follow the Gaussian distribution curve, the Mann Whitney non-parametric test and Pearson correlations were run using SPSS (IBM SPSS Statistical software Version 19. Copyright 1989, 2010 SPSS Inc). Results are reported as mean \pm SD.

\section{Results}

The demographics of the children are displayed in Table 1 . Seven children had confirmed GH deficiency based on a blunted peak GH response of $<10 \mathrm{ng} / \mathrm{ml}$ to two provocative tests (peak GH $6.62 \pm 2.08 \mathrm{ng} / \mathrm{ml}$ ). The remaining children were GH sufficient with a peak GH of $22.28 \pm 12.17 \mathrm{ng} / \mathrm{ml}$. One child underwent GH stimulation testing after adult height was achieved to identify if GH was indicated.

Figure 1(a) demonstrates TNF alpha concentrations and GH concentrations in GH sufficient patients and Figure 1(b) demonstrates TNF alpha and GH concentrations in GH deficient patients. Baseline TNF $\alpha$ levels in the GH sufficient subjects $(12.39 \pm 12.85 \mathrm{pg} / \mathrm{ml})$ did not differ significantly from baseline TNF $\alpha$ levels in the GH deficient children $(15.18 \pm 12.21 \mathrm{pg} / \mathrm{ml})(\mathrm{p}=0.42)$ (Figure 2). There was no correlation between peak TNF $\alpha$ and peak GH levels during stimulation testing in all subjects as a whole $(r=-0.09)$ nor in GH sufficient or GH deficient children.

Comparison of baseline concentrations of the following analytes between GH deficient and GH sufficient subjects revealed no significant differences: CRP $(p=0.31)$, IL-6 ( $p=0.83)$, Il-1 $\beta(p=0.80)$, IL-10 $(p=0.71)$

Table 1. Demographics table.

\begin{tabular}{cccc} 
& All subjects $(\boldsymbol{n}=\mathbf{2 3})$ & GH deficient $(\boldsymbol{n}=\mathbf{7})$ & GH sufficient $(\boldsymbol{n}=\mathbf{1 6})$ \\
\hline Age in years (range) & $10.3(5.0-16.8)$ & $9.5(5.6-15.1)$ & $10.6(5.0-16.8)$ \\
Sex $(\mathrm{M} / \mathrm{F})$ & $16 / 7$ & $4 / 3$ & $12 / 4$ \\
Height in cm \pm SD & $126 \pm 18.9$ & $120.1 \pm 13.1$ & $128.6 \pm 20.7$ \\
Other hormone deficiencies & 2 & 1 & 1 \\
Reagent: & 15 & 5 & 6 \\
Arginine & 8 & 2 & 16 \\
Glucagon & 23 & 7 & 16 \\
Clonidine & & & \\
\hline
\end{tabular}

Pain score 0 for all patients. 


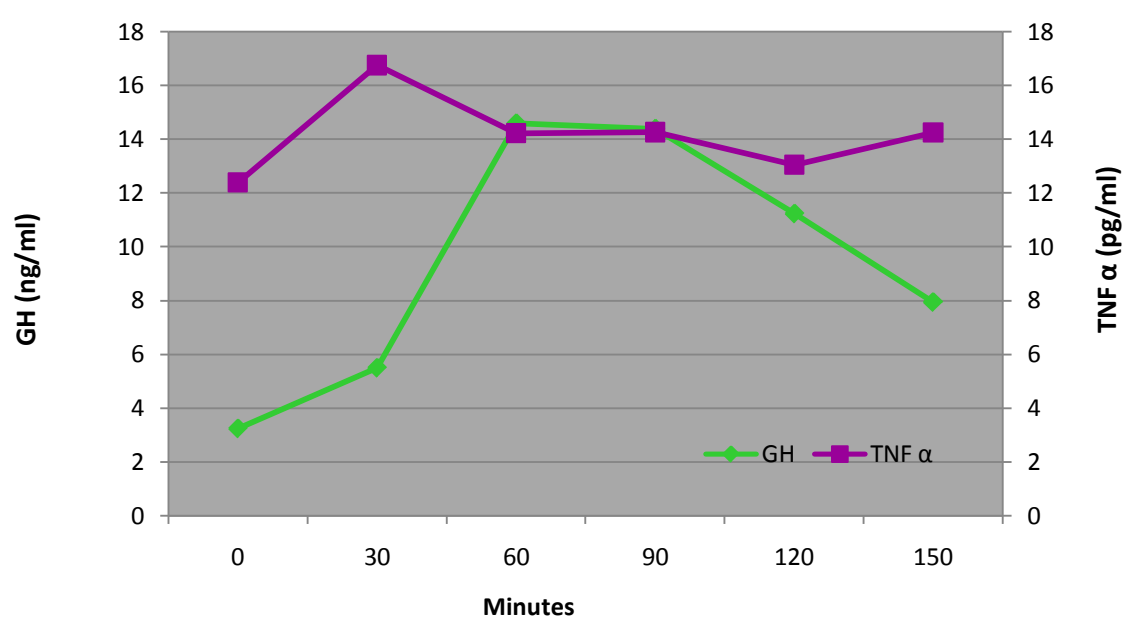

(a)

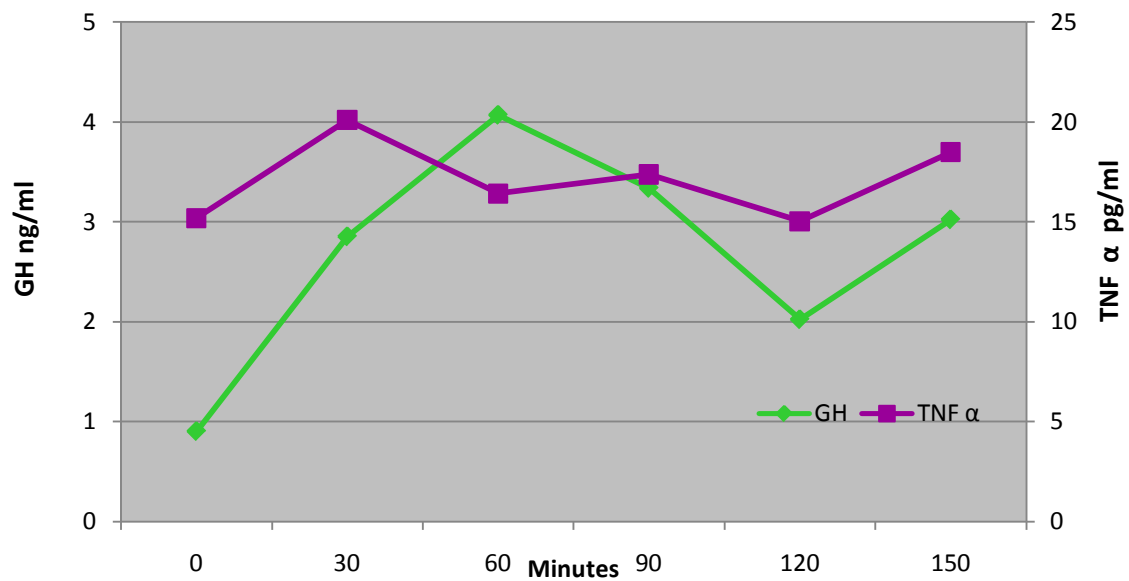

(b)

Figure 1. (a) Relationship between mean GH (ng/ml) and TNF $\alpha$ (pg/ml) during GH stimulation testing in GH sufficient patients. (b) Relationship between mean GH (ng/ml) and TNF $\alpha(\mathrm{pg} / \mathrm{ml})$ during GH stimulation testing in GH deficient patients.

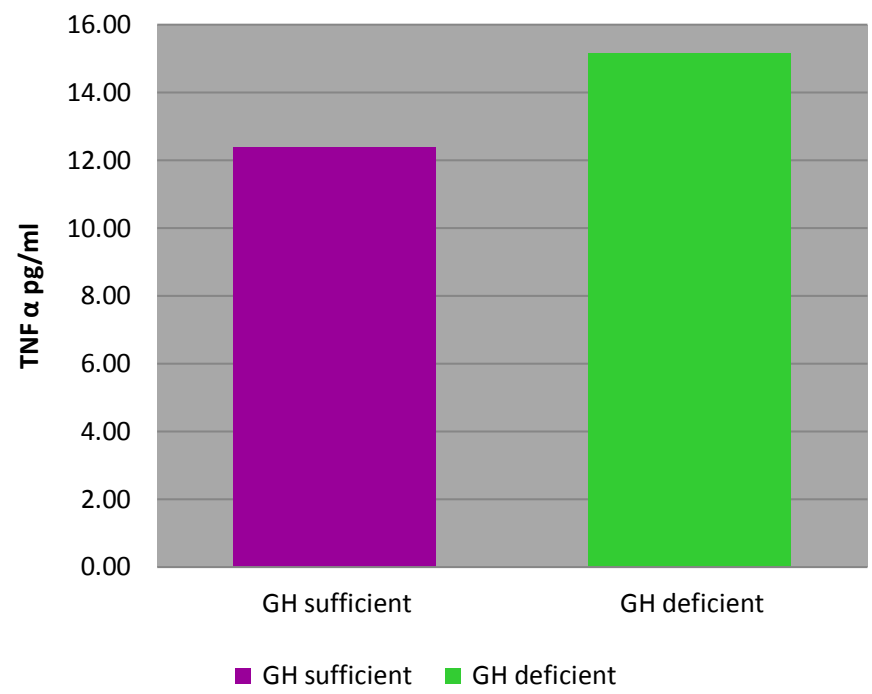

Figure 2. Baseline TNF $\alpha$ levels in GH sufficient versus GH deficient patients. 
and IL-4 $(p=0.80)$. GH levels did not correlate with pro inflammatory cytokines CRP $(r=0.21)$, IL-6 ( $r=-0.07)$, or IL-1 $\beta(r=-0.12)$ or anti-inflammatory cytokines IL-10 $(r=-0.23)$ and IL-4 $(r=-0.19)$. In 6 of 16 GH sufficient patients in whom sTNFRII was measured there was no relationship between peak GH level and sTNFRII. As a result of these negative findings in GH sufficient patients, the relationship between peak GH and sTNFRII was not explored in the remaining GH sufficient patients or the GH deficient patients.

\section{Discussion}

Our study is unique in that it is the only study looking at endogenous GH secretion and its relationship to TNF $\alpha$ and pro-inflammatory cytokines CRP, IL- $1 \beta$ and IL-6 as well as anti-inflammatory cytokines IL-10 and IL-4 during GH stimulation testing.

Our results did not reveal an acute relationship between endogenous GH and TNF $\alpha$ levels. Our findings are similar to those demonstrated by Michalacous et al. in which GH did not correlate with TNF $\alpha$ in GH deficient children or in short stature children as a group [8]. Ramos et al. also failed to identify a relationship between acute GH administration and cytokine production in a population of healthy young men [7].

Unlike studies performed by Andiran et al., our study did not demonstrate differences in basal TNF $\alpha$ concentrations between GH sufficient and GH deficient children [9]. Our findings are supported by Bozzola et al. who also established no difference in baseline TNF $\alpha$ or IL-1 $\beta$ between GH deficient children and healthy controls. However, this same group illustrated increased TNF $\alpha$ and IL- $1 \beta$ production with short term GH administrationsignifying that GH may play along term role in modulating TNF $\alpha$ and IL- $1 \beta$ secretion [11]. Our study did not reveal any difference in baseline concentrations of either other pro- or anti-inflammatory cytokines in GH deficient versus GH sufficient patients or any relationship between acute endogenous GH secretion and these cytokines.

Cytokine production and its effect on cardiovascular risk factors have recently gained more attention within the literature. Adults with growth hormone deficiency have been shown to have increased prevalence of atherosclerosis and cardiovascular morbidity. Monocytes appear to play a contributory role in early development of atherosclerosis as well as production of proatherogenic cytokines [14]. Research has demonstrated that plasma concentrations of both TNF alpha and IL-6 are increased in GH deficient adults. The increased plasma concentrations are secondary to increased monocyte production of both of these cytokines [15]. Serri et al. showed a positive correlation between plasma TNF $\alpha$ and IL-6 levels and monocyte TNF $\alpha$ and IL-6 production in GH deficient adults. The abnormally elevated TNF $\alpha$ and IL-6 levels improved with GH supplementation [15]. Currently, there is limited data available regarding the presence of peripheral inflammatory markers and its contribution to future cardiovascular disease in GH deficient adolescents and children. Lanes et al. compared cytokine levels in a population of untreated GH deficient adolescents, treated GH deficient adolescents and healthy controls [16]. CRP, TNF $\alpha$, and fibrinogen levels were equally elevated in all adolescents with GH deficiency suggesting the inflammatory response may begin as early as adolescence and may not be reduced with GH supplementation [16].

Our results may have been impacted by the reagents used for GH stimulation testing. Studies that have evaluated the impact of $\alpha 2$ agonists, such as clonidine, on cytokine production are conflicting. Pre-operative administration of clonidine resulted in decreased TNF $\alpha$ production in plasma and cerebrospinal fluid [17]. Similarly, Xu et al. showed reduction in TNF $\alpha$, IL-10 and IL-6 in pre-eclamptic placentas of women treated with increasing doses of clonidine [18]. However, this same group also reported no change in TNF $\alpha$ production from placentas and peripheral blood mononuclear cells of healthy women treated with clonidine [19]. To the contrary, UK-14304, a $\alpha 2$ agonist augmented lipopolysaccharide stimulated TNF $\alpha$ production from murine macrophages in vitro [20]. Given the inconsistent documentation in the literature regarding the effects of $\alpha 2$ agonists on cytokine production, it is difficult to know what impact clonidine may have had on our cytokine results. In addition, our negative results may have been impacted by the short duration of the GH stimulation test. Cytokine kinetics in whole blood models demonstrated that stimulated peak TNF $\alpha$ levels occurred 2 hours after endotoxin challenge, suggesting that 150 min may not be sufficient time for priming of macrophages for TNF $\alpha$ secretion [21]. Kappel et al. induced a significant increase in neutrocyte count two hours after a bolus infusion of recombinant GH but failed to show an increase in cytokine production indicating GH may only have minor acute effects on the immune system [22]. Numerous in vitro and in vivo studies have suggested GH modulates cytokine secretion [3] [5] [6] [11] [23]. All of these studies used pharmacologic doses of GH that would have exceeded the 
endogenously produced serum concentrations seen in most of our subjects. Studies have shown the half-life of TNF $\alpha$ to be $15.9 \pm 3.6 \min$ to $17 \pm 2$ min [24]. Our inability to identify an acute relationship between TNF $\alpha$ and GH may also have been influenced by the pharmokinetics of the TNF $\alpha$ molecule. Finally, our results may be limited by our small sample size.

\section{Conclusion}

Our study did not identify an acute relationship between acute endogenous GH secretion and the pro-inflammatory cytokines, CRP, IL-6, or IL- $1 \beta$ or anti-inflammatory cytokines IL-10 and IL-4 in short children undergoing an evaluation for GH deficiency.

\section{Disclosures}

The authors have no financial or non-financial competing interests.

\section{References}

[1] Walton, P.E. and Cronin, M.J. (1989) Tumor Necrosis Factor-Alpha Inhibits Growth Hormone Secretion from Cultured Anterior Pituitary Cells. Endocrinology, 125, 925-929. http://dx.doi.org/10.1210/endo-125-2-925

[2] Scarborough, D. (1990) Cytokine Modulation of Pituitary Hormone Secretion. Annals of the New York Academy of Sciences, 594, 169-187. http://dx.doi.org/10.1111/j.1749-6632.1990.tb40477.x

[3] Edwards, C.K., et al. (1991) Hypophysectomy Inhibits the Synthesis of Tumor Necrosis Factor Alpha by Rat Macrophages: Partial Restoration by Exogenous Growth Hormone or Interferon Gamma. Endocrinology, 128, 989-986. http://dx.doi.org/10.1210/endo-128-2-989

[4] Kooijman, R., et al. (1992) Expression of Type I Insulin-Like Growth Factor Receptors on Human Peripheral Blood Mononuclear Cells. Endocrinology, 131, 2244-2250.

[5] Bozzola, M., et al. (2003) Stimulating Effect of Growth Hormone on Cytokine Release in Children. European Journal of Endocrinology, 149, 397-401. http://dx.doi.org/10.1530/eje.0.1490397

[6] Pagani, S., et al. (2005) Serum Cytokine Levels in GH-Deficient Children during Substitutive GH Therapy. European Journal of Endocrinology, 152, 207-210. http://dx.doi.org/10.1530/eje.1.01827

[7] Ramos, S.B., Brenu E.W., Christy, R., et al. (2011) Assessment of Immune Function after Short Term Administration of Recombinant Growth Hormone in Healthy Young Males. European Journal of Applied Physiology, 111, 1307-1312. http://dx.doi.org/10.1007/s00421-010-1756-4

[8] Michalacos, S., et al. (2002) Tumor Necrosis Factor-Alpha Levels in Short Children. Journal of Pediatric Endocrinology and Metabolism, 15, 193-196. http://dx.doi.org/10.1515/JPEM.2002.15.2.193

[9] Andiran, N. and Yordam, N. (2007) TNF-Alpha Levels in Children with Growth Hormone Deficiency and the Effect of Long-Term Growth Hormone Replacement Therapy. Growth Hormone \& IGF Research, 17, 149-153. http://dx.doi.org/10.1016/j.ghir.2007.01.002

[10] Zarkesh-Esfahani, S.H., et al. (2000) High-Dose Growth Hormone Does Not Affect Proinflammatory Cytokine (Tumor Necrosis Factor-Alpha, Interleukin-6, and Interferon-Gamma) Release from Activated Peripheral Blood Mononuclear Cells or after Minimal to Moderate Surgical Stress. Journal of Clinical Endocrinology \& Metabolism, 85, 3383-3390.

[11] Bozzola, M., De Amici, M., Zecca, M., Schimpff, R. and Rapaport, R. (1998) Modulating Effect of Human Growth Hormone on Tumour Necrosis Factor-Alpha and Interleukin-1 $\beta$. European Journal of Endocrinology, 138, 640-643. http://dx.doi.org/10.1530/eje.0.1380640

[12] Chrysopoulo, M.T., Jeschke, M.G., Ramirez, R.J., et al. (1999) Growth Hormone Attenuates Tumor Necrosis Factor Alpha in Burned Children. Archives of Surgery, 134, 283-286. http://dx.doi.org/10.1001/archsurg.134.3.283

[13] Hardin, D.S., Ellis, K.J., Dyson, M., et al. (2001) Growth Hormone Decreases Protein Catabolism in Children with Cystic Fibrosis. The Journal of Clinical Endocrinology \& Metabolism, 86, 4424-4428. http://dx.doi.org/10.1210/jcem.86.9.7822

[14] Ross, R. (1993) The Pathogenesis of Atherosclerosis: A Perspective for the 1990s. Nature, 362, 801-809. http://dx.doi.org/10.1038/362801a0

[15] Serri, O., St-Jacques, P., Sartippour, M., et al. (1999) Alterations of Monocyte Function in Patients with Growth Hormone (GH) Deficiency: Effect of Substitutive GH Therapy. The Journal of Clinical Endocrinology \& Metabolism, 84, 58-63. http://dx.doi.org/10.1210/jc.84.1.58

[16] Lanes, R., Paoli, M., Carrillo, E., et al. (2004) Peripheral Inflammatory and Fibrinolytic Markers in Adolescents with 
Growth Hormone Deficiency: Relation to Postprandial Dyslipidemia. Journal of Pediatrics, 145, 657-661. http://dx.doi.org/10.1016/j.jpeds.2004.07.037

[17] Nader, N.D., Ignatowski, T.A., Kurek, C.J., et al. (2001) Clonidine Suppresses Plasma and Cerebrospinal Fluid Concentrations of TNF-Alpha during the Perioperative Period. Anesthesia \& Analgesia, 93, 363-369.

[18] Xu, B., Thornton, C., Makris, A., Ogle, R. and Hennessy, A. (2007) Anti-Hypertensive Drugs Alter Cytokine Production from Preeclamptic Placentas and Peripheral Blood Mononuclear Cells. Hypertension in Pregnancy, 26, 343-356. http://dx.doi.org/10.1080/10641950701380958

[19] Xu, B., Makris, A., Thornton, C., et al. (2006) Antihypertensive Drugs Clonidine, Diazoxide, Hydralazine and Furosemide Regulate the Production of Cytokines by Placentas and Peripheral Blood Mononuclear Cells in Normal Pregnancy. Journal of Hypertension, 24, 915-922. http://dx.doi.org/10.1097/01.hjh.0000222762.84605.03

[20] Spengler, R.N., Allen, R.M., Remick, D.G., Strieter, R.M. and Kunkel, S.L. (1990) Stimulation of Alpha-Adrenergic Receptor Augments the Production of Macrophage- Derived Tumor Necrosis Factor. Journal of Hypertension, 145, 1430-1434.

[21] Oliver, J.C., Bland, L.A., Oettinger, C.W., et al. (1993) Cytokine Kinetics in an in Vitro Whole Blood Model Following an Endotoxin Challenge. Lymphokine \& Cytokine Research, 12, 115-120.

[22] Kappel, M., Hansen, M.B., Diamant, M., et al. (1993) Effects of an Acute Bolus Growth Hormone Infusion on the Human Immune System. Hormone and Metabolic Research, 25, 579-585. http://dx.doi.org/10.1055/s-2007-1002181

[23] Tripathi, A. and Sodhi, A. (2009) Growth Hormone-Induced Production of Cytokines in Murine Peritoneal Macrophages in Vitro: Role of JAK/STAT, PI3K, PKC and MAP Kinases. Immunobiology, 214, 430-440. http://dx.doi.org/10.1016/j.imbio.2008.11.013

[24] Rosenblum, M.G. and Donato, N.J. (1989) Tumor Necrosis Factor Alpha: A Multifaceted Peptide Hormone. Critical Reviews in Immunology, 9, 21-44. 